\title{
A Review of Color Science in Dentistry: Shade Matching in the Contemporary Dental Practice
}

\author{
James C. Ragain* \\ Department of Restorative Dentistry, University of Tennessee Health Sciences Center, College of Dentistry, Memphis, TN
}

Received: June 20, 2016; Accepted: July 06, 2016; Published: July 15, 2016

*Corresponding author: James C. Ragain Jr., D.D.S., M.S., Ph.D., Associate Professor, Department of Restorative Dentistry, University of Tennessee Health Sciences Center, College of Dentistry, Memphis, TN; Tel no: +901-448-1323; E-mail: jragain@uthsc.edu

\begin{abstract}
This article is the third in a series of review articles discussing the applications of color science to the clinical practice of dentistry. This installment discusses contemporary techniques for shade selection of teeth, as well as, challenges to successful clinical matching of the tooth shade to dental restorative materials.
\end{abstract}

\section{Introduction}

This article is the third in a series of articles that will review the fundamentals of color science as applied to the practice of dentistry. The first article discussed the basic human perception of color and reviewed the current accepted theory of human color perception [1]. The second article reviewed the measurement color, color difference calculations, and the principles of colorimetry [2]. This article discusses the contemporary techniques and challenges of clinically determining the color of teeth, as well as, matching tooth shade to dental restorative materials. The common theme for all three of the articles is that an understanding of the principles of color vision, color measurement, and the communication of color parameters will improve the restorative dentist's abilities to meet patient expectations for biomimetic dental restorations.

The restoring of form and function of the dentition for dental patients should be at the forefront of restorative dental care. However, patients generally have high expectations for excellent esthetic results. The incorporation of restorative materials with the teeth resulting in a natural appearance in which the dental restorative materials blend without detection should also be a major goal of the restorative dentist [3].

Restorative dental materials and prostheses matched to patient tooth color using contemporary clinical techniques generally provide results acceptable by most patients $[4,5,6,7,8,9,10,11,12,13]$. However, visual shade guides with shade tabs are commonly used for shade selection and these techniques are very subjective, and often these techniques depend on numerous ambient factors and the color vision acuity of the clinician. In the contemporary restorative dental practice, colorimetric instrumentation can be used to choose a close color match. This article will discuss the visual and automatic device techniques available for shade selection. It is recommended that the first two articles in this series be reviewed to better understand the concepts of color theory and colorimetry applied to shade matching.

\section{Materials and Methods}

\section{Manual, Visual Shade Selection Techniques}

The most frequently used technique in the shade matching of teeth to restorative materials is done manually and visually with dental shade guides [14]. Using this method, shade matching is accomplished by visually comparing a tooth with multiple standards, usually represented as shade guide tabs, Figure 1. The shade selection done in this fashion is subjective and is influenced by the ability of the human observer to choose the best matching shade. Factors such as observer color perception, observer bias, ambient lighting, and the acceptance threshold of mismatch have effects on accurate shade matching. Also, not all commercial shade guides cover all the ranges of value, hue, and chroma present in human tooth structure [15]. The aging of these shade guides combined with potential "darkening" of the tabs due to cold sterilization create havoc if undiscovered. The original shade guides represented only about 30 percent of the color range of natural dentition. This range has improved tremendously with the advances in colorimetry and improved shade guides. None of the currently available laboratory restorative material systems are available in more than two shade systems with many available in only one. Quite often this creates the need for "cross-matching" which requires the

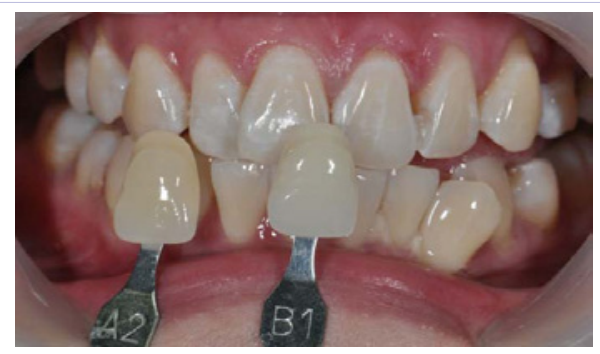

Figure 1: Dental shade Matching Tabs (Vita Classical A1- D4®). 
laboratory technologist to reformulate the material shades to match the particular dentition. This is an extremely subjective process which could lead to unacceptable mismatches. Another problem is the influence of shade designation on the difference in color in various brands of dental restorative materials. Kim and Lee [16] found inconsistency in the color of the same shade designation of composite resin materials by manufacturer brand. This should be taken into consideration when selecting shades of these materials clinically.

There are a variety of shade guides available to the practitioner. Three examples are illustrated in Figure 2. Some are universal shade guides in that they could be used for matching ceramic materials and composite resin materials with teeth. However, it is usually beneficial to use a shade guide made of the corresponding restorative material. Examples of resinmade shade guides are Esthet- $\mathrm{X}^{\circledR}$ (Densply/Caulk, Milford, DL, USA) Tetric Cream $^{\circledR}$ (Coltene/Whaledent, Cuyahoga Falls, OH, USA), Venus ${ }^{\circledR}$ (Haeraus Kulzer, South Bend, ID, USA), and Vit-lescence ${ }^{\circledR}$ (Ultradent, South Jordan, UT, USA). The ceramic made shade guides include the Vita line of shade guides (Vita North America, Yorba Linda, CA, USA), Chromoascop ${ }^{\circledR}$ (Ivoclar Vivadent, Amherst, NY), and Vintage Halo ${ }^{\circledR}$ (Shofu Dental, Menlo Park, CA). Many of the manual, visual shade guides have similar design and functionality, so we will concentrate on one line of products to illustrate the manual, visual shade selection technique.

The VITA Classical A1-D $4{ }^{\circledR}$ shade guide (Vita North America, Yorba Linda, CA, USA) was introduced to dentistry in 1956, Figure 3. The VITA Classical A1-D $4{ }^{\circledR}$ is composed of sixteen tabs. The tabs are arranged into four groups (A-D) based on hue with increasing chroma within the groups. In this arrangement, Group A is reddish-brown, Group B is reddish-yellow Group C is gray, and Group D is reddish-Gray. As described by Paravina and
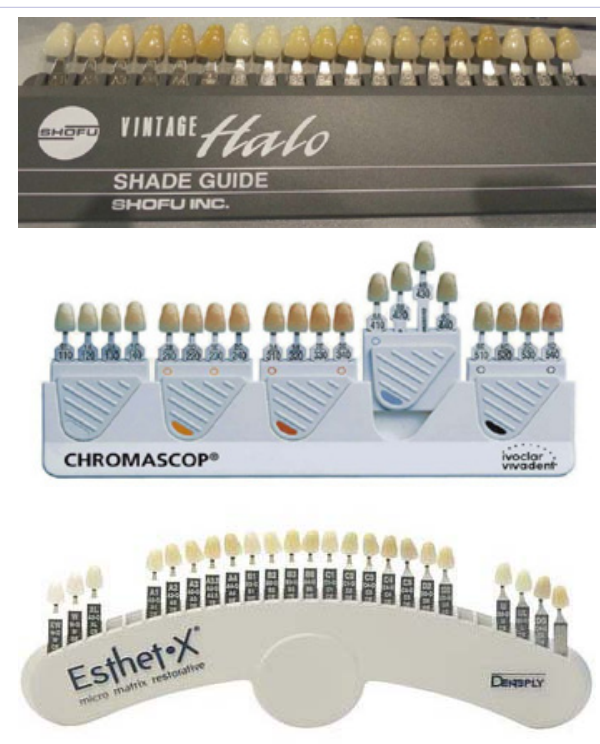

Figure 2: Examples Of Three Manual, Visual Shade Guides Used in Dentistry.

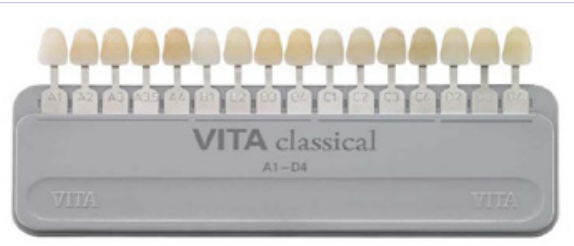

Figure 3: VITA Classical A1-D4 Shade Guide ${ }^{\circledR}$ (Vita North America, Yorba Linda, CA, USA).

Powers, the manufacturer also provides an arrangement of shade guide tabs by hue [15]. Many dentists find that matching tooth shades is simplified by this arrangement of tabs, and this array of tabs by degree of brightness has been found to be easier and more reliable to use, Figure 4 [15].

In the 1990's, Vita North America enhanced their shade guide system and introduced the VITA System 3-D MASTER shade guides $^{\circledR}$. This system is composed of the VITA Linear guide 3-D MASTER $^{\circledR}$, the VITA Bleach guide 3-D MASTER ${ }^{\circledR}$, and the VITA Tooth guide 3D-MASTER ${ }^{\circledR}$ with Bleached Shades, Figure 5. The VITA System 3-D MASTER ${ }^{\circledR}$ shade guides consist of 26 shade tabs in five groups according to lightness. Within each group, the tabs are arranged vertically according to chroma and horizontally according to hue. The concept of the VITA 3D-MASTER ${ }^{\circledR}$ system is based on a color classification principle where the values of lightness, chroma, and hue have been positioned an equal distance from each other. Therefore, the shade determination can be easily carried out according to systematic criteria.

The VITA Linear guide 3-D MASTER ${ }^{\circledR}$ simplifies tooth shade determination compared to the VITA Classical A1-D4 and the VITA Tooth guide 3D-MASTER ${ }^{\circledR}$ Figure 6 with Bleached Shades. It is organized in terms of lightness, chroma, and hue, and the shade can be determined in two steps. The VITA Bleach guide 3-D MASTER ${ }^{\circledR}$ with Bleached Shades is a one-step process to determine the level of lightness for the tooth whitening process.

When comparing the VITA 3-D MASTER ${ }^{\circledR}$ system with the VITA Classical A1-D $4{ }^{\circledR}$ shade guide it can be noted that the value range is wider, there are more chromatic tabs, the hue range is extended into the reddish color spectra, there is more uniformity in the shade tab spacing, and the overall tab arrangement is improved over the VITA Classical A1-D-4 ${ }^{\circledR}[16]$.

In general, when using shade guides to select a shade, it is recommended that hue selection be made first, followed by chroma and value, in that order. The clinician should always do a final check and revise the shade selection if needed. The following are recommendations for shade selection in the dental operatory:

- Teeth to be matched must be clean.

- Remove bright colors from the field of view.

- Tooth shade should be determined in daylight or under standardized daylight lamps (not operation lamps).

- Operatory walls should be neutral in color. 


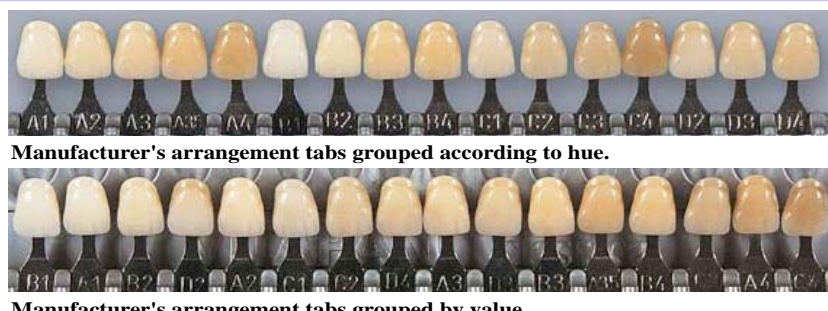

M anufacturer's arrangement tabs grouped by value.

Figure 4: Two typical tab arrangements of the VITA Classical A1D4®shade guide. (Derived from Paravina RD, Powers JM (2004). Esthetic Color Training in Dentistry. St. Louis MO, USA: Elsevier Mosby.)

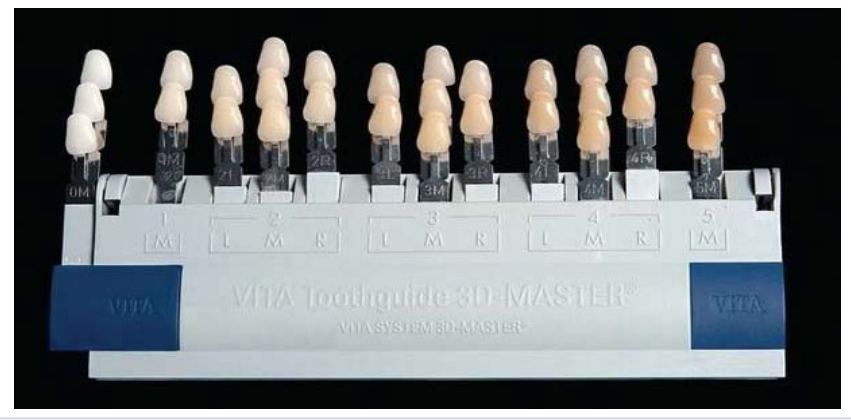

Figure 5: VITA Toothguide 3-D MASTER with Bleached Shades ${ }^{\circledR}$.

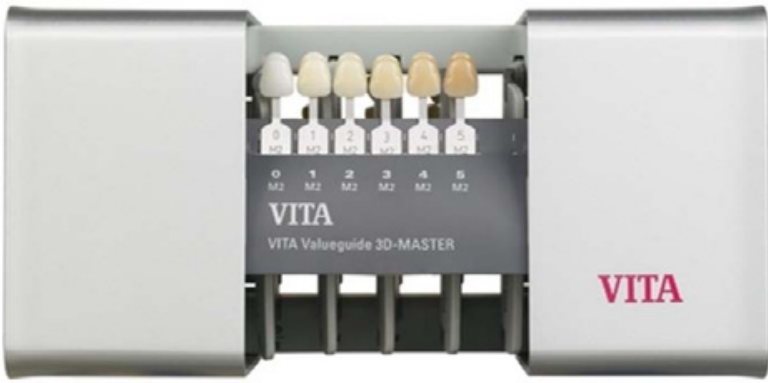

Figure 6: VITA Linearguide 3-D MASTER ${ }^{\circledast}$.

- View at the patient eye level.

- Evaluate shade under multiple light sources.

- Make shade matching at the beginning of treatment before the teeth begin to dehydrate.

- Shade matching should be made quickly to avoid eye fatigue (5-7) seconds. The observer can look at a blue or gray card to rest eyes.

\section{Automatic, Instrumental Shade Selection Techniques}

There are three primary categories of automatic shade selection devices. These shade matching instruments were introduced to the dental profession to overcome the limitations and inconsistencies of the manual, visual shade matching systems [17]. Those instruments can be classified as colorimeters, spectrophotometers, and digital imaging devices. The measurement of color using colorimeters and spectrophotometers is explained in detail in the second article in this series [2].

There are pros and cons for using these instruments in the dental practice. These issues are clearly outlined by Chu, et al. ${ }^{17}$ The dentist must consider how the technology relates to clinical expectations and requirements. One issue associated with these instruments is the phenomena of edge loss effects. As described by Bolt et al. [18], these instruments a have a small edge loss of light, resulting in systematic errors in color coordinates. Edgelosses occur during reflectance measurements of translucent materials when light is scattered within a sample beyond that part of the surface exposed to the observation system of the optical colorimetric instrument [19]. Colorimeters and spectrophotometers measure color with a small window for illumination and measurement resulting in the edge loss effects. One study looked at minimizing the optical measurement errors caused by edge loss effect, scattering of light, and instrument variations in positioning [20]. It was determined in this study that a colorimeter equipped with a custom-made positioning jig improved the precision for intraoral measurement of longitudinal tooth color changes. These instruments can be much higher in price then the manual shade guide systems.

Colorimeters measure the tristimulus values, filtering light in the red, green, and blue areas of the visual color spectrum. Since colorimeters do not register total visual light spectral reflectance, they can be less accurate than spectrophotometers. ${ }^{17}$ The first colorimeter designed for color selection in dentistry (Chromascan, ${ }^{\circledR}$ Terngold, Stamford, CT, USA) was not very successful. Its accuracy was limited and the user interface was challenging for most dentists [17]. Contemporary clinical colorimeters are much improved. The ShadeVison ${ }^{\circledR}(\mathrm{X}$-Rite, Grandville, MI, USA) and ShadeEye NCC ${ }^{\circledR}$ (Shofu, Menlo Park, CA, USA) are two of these colorimeters, Figure 7.

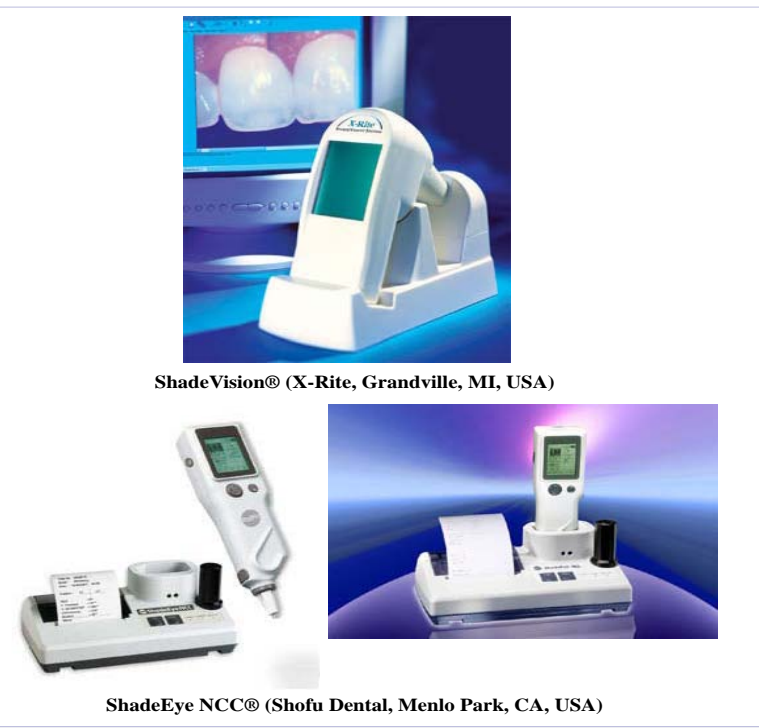

Figure 7: Two Examples of Dental Clinical Colorimeters. 
Spectrophotometers measure the amount of light energy reflected from an object's surface at $1-25 \mathrm{~nm}$ intervals along the visual light spectrum $(380-780 \mathrm{~nm})[21,22]$. They can be the most accurate instrument for color matching in dentistry [23] Included in a clinical spectrophotometer is an illuminant source, a mechanism for dispersing light, a system to measure and convert the reflected light flux to a signal for analysis [17].The resultant color measurements can be keyed to the various dental shade guides and converted to an equivalent of the respective shade tab [24].

There are several very high quality and reliable clinical spectrophotometers available. Two of them, the VITA EasyShade Compact $^{\circledR}$ (Vita North America, Yorba Linda, CA, USA) and CrystalEye ${ }^{\circledR}$ (Olympus America, Center Valley, PA, USA), are shown in Figure 8.

The third classification of automated shade selection devices are the digital cameras and imaging systems. Digital cameras are based on the RGB color model in which the camera obtains red, green, and blue data that is used to produce the color image. In this additive color model [2] red, green, and blue light are added together to generate a broad arrangement of colors. Digital cameras provide a basic approach to electronic shade selection and require a degree of shade selection with the human observer [17]. The use in the dental practice of commercially available digital cameras can be very appealing to the clinician due to the cost, ease of use, and availability of digital cameras. Color accuracy of three digital cameras compared to spectrophotometric CIE LAB measurements was studied by Wee et al. [25] in which four regression models were formulated from the CIE LAB and camera digital image values. Shade tab CIE LAB colors were predicted by applying the digital values into the calibration models and were compared to the measured CIELAB values. They determined that there is potential for the use in clinical dentistry of digital cameras combined with appropriate calibration protocols. A recent study [26] used regression models to relate the RGB data from a camera to spectroradiometric counterparts in CIE XYZ and absolute reflectance. The authors found a strong correlation relationship between RGB and lightness for shade guides. Their regression models allow tooth color information to be translated from digital images to accurate shade guide tabs for clinical color

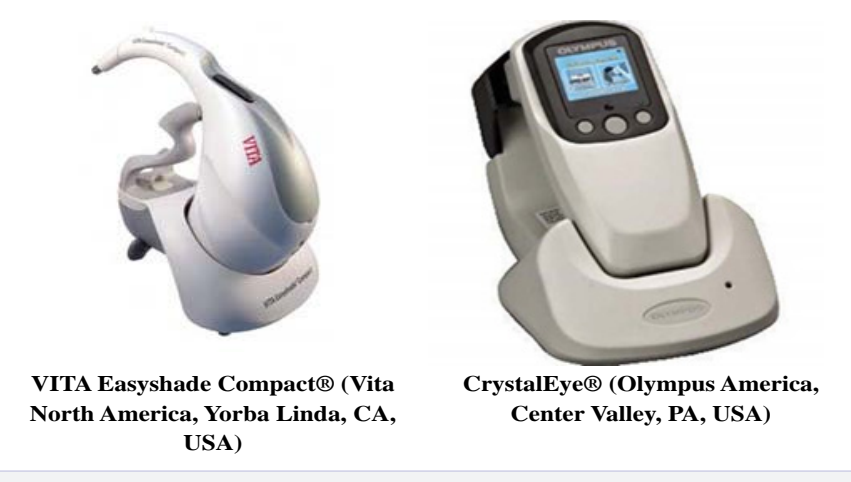

Figure 8: Two Examples of Dental Clinical Spectrophotometers. matching. This will enhance the removal of the subjective aspect of color matching.

Digital scanners such as those used in computer aided designcommuter aided manufacturing (CAD-CAM) systems are also being developed with tooth shade selection capabilities. This could be extremely beneficial as digital dentistry techniques are incorporated into dental practice.

The manufacturer instructions should always be followed when using color matching instruments. In general, there is not as much ambient influence using these devices as there is in using the manual shade guides. However, the teeth being matched should be cleaned prior to taking a reading.

\section{Comparison of Manual and Mechanical Shade Selection Techniques}

Both visual and instrumental systems have greatly improved over the past twenty years. As previously mentioned, the manual, visual shade guide systems continue to be the most common means of shade selection in dentistry. The visual systems are much cheaper to obtain. However, shade selection is very subjective and is heavily influenced by ambient conditions. With the addition of today's advanced colorimetry technology, qualitative and quantitative reliability more than doubles to approximately 70 percent of the true color range of natural dentition. Recently better results were reported with a dental spectrophotometer than the visual method [13,17]. One study [27] compared the repeatability and inter-device reliability between a colorimeter (ShadeEye NCC ${ }^{\circledR}$ ) and a spectrophotometer (VITA EasyShade Compact $\left({ }^{\circledR}\right)$. High repeatability of the CIE $L^{*} a^{*} b^{*}$ values was found for both instruments. However the instruments demonstrated different $L^{*} a^{*} b^{*}$ values and shades for the same tooth. They found that lightness $\left(\mathrm{L}^{*}\right)$ affects inter-device reliability. Another study which compared the reliability and accuracy of four clinical shade matching instruments (two clinical spectrophotometers and two colorimeters) [28] found variations in both reliability and accuracy of the devices. Most device comparisons demonstrated high reliability which would indicate predictable shade values when repeating the measurements. However, when comparing the devices for accuracy, there was pronounced variability between the devices. It has been recommended that both visual and mechanical shade selection system be incorporated into the contemporary dental practice as they complement each other [17].

\section{Conclusion}

It is hoped that this three-part article series reviewing the application of color science to dentistry was beneficial to the practicing restorative dentist. Close shade matching of dental restorative materials with natural teeth is vital to producing restorations that are biomimetic. Patients expect the modern dentist to restore missing and broken down teeth to and proper form and function with an acceptable esthetic appearance. A better understanding of the physical and physiological processes involved in human color vision, color theory, and colorimetry 
should enhance an appreciation for the challenges associated with tooth shade selection.

\section{References}

1. Ragain JC. A review of color science in dentistry:The process of color vision. J Dent Oral Disord Ther. 2015;3(1):1-4.

2. Ragain JC. A review of color science in dentistry:Colorimetry and color space. J Dent Oral Disord Ther. 2016;4(1):1-5.

3. MacAdams DL. Color measurement, theme and variations. New York, NY, USA: Springer-Verlag; 1981.

4. Ragain JC. Matching the optical properties of direct esthetic dental restorative materials to those of human enamel and dentin. A dissertation for the partial fullfillment of the requirement for the nfdegree Doctor of Philosophy in the Graduate School of The Ohio State University: Columbus, OH. 1998.

5. Ragain JC, Johnston WM. Minimum color differences for discriminating mismatch between composite and tooth color. J Esthetic Dent. 2001;13(1):41-48.

6. Ragain JC and Johnston WM. Color acceptance of direct restorative materials by human observers. Color Res and Appl. 2000;25(4):278285.

7. Johnston WM, Kao EC. Assssment of appearance match by visual observation and clinical colorimetry. J Dent Res. 1989;68(5):819-822.

8. Ruyer IE, Nilner K, Moller B. Color stability of dental composite resin materials for crown and bridge veneers. Dent Mater. 1987;3(5):246251.

9. Kuehni RG, Marcus RT. An experiment in visual scaling of small color differnces . Color Res and Appl. 1979;4(2):83-91.

10. Seghi RR, Hewlett ER, Kim J. Visual and instrumental colorimetric assessments of small color differences on translucent dental porcelain. J Dent Res. 1989;68(12):1760-1764.

11.0'Brien WJ, Groh CL, Boenke KM. A new, small-color-difference equation for dental shades. J Dent Res. 1990;69(11):1762-1764.

12. Douglas RD, Steinhauser TJ, Wee AG. Intraoral determination of the tolerance of dentists for perceptibility and acceptability of mismatch. J Prosth Dent. 2007;97(4):200-208.

13. Da Silva JD, Park SE, Weber HP, Ishikawa-Nagai S. Clinical performance of a newly developed spectrophotometric system on tooth color reproduction. J Prosth Dent. 2008;99(5):361-368.

14. Paravina RD. Performance assessment of dental shade guides. J of Dent. 2009;37s:e15-e20.
15. Paravina RD, Powers JM. Esthetic Color Training in Dentistry. St. Louis MO, USA: Elsevier Mosby; 2004.

16. Kim BJ, Lee YK. Influence of the shade designation on the color difference between the same shade-designated resin composites by the brand. Dent Mater. 2009;25(9):1148-1154

17. Yuan JC, Brewer JD, Monaco EA, Davis EL. Defining a natural tooth color space based on a 3-dimensional shade system. J Prosthet Dent. 2007;98(2):110-119.

18. Chu SJ, Trushkowsy RD, Paravina RD. Dental color matching instruments and systems. Review of clinical and research aspects. J of Dent. 2010;38s:e2-e16.

19. Bolt RA, Tenbosch JJ, Coops JC. Influence of window size in smallwindow colour measurement, particularly in teeth. Phys.Med.Biol. 1994;39(7):1133-1142.

20. Johnston WM, Hesse NS, Davis BK, Seghi RR. Analysis of edge-losses in reflectance measurements of pigmented maxillofacial elastomer.J Dent Res. 1996;75(2):752-760.

21. Douglas RD. Precision of in vivo colorimetric assessments of teeth. J Prosthet Dent. 1997;77(5):464-470.

22. Khurana R, Tredwin CJ, WeisbloomM, Moles DR. A clinical evaluation of the individual repeatibilityof three commercially available color measuring devices. Brit Dent J. 2007;203:675-680.

23. Kielbassa AM, Beheim-Schwarzbach NJ, Neumann K, Zantner C. In vitro comparison of visual and computer-aided pre- and post-tooth shade determination using various home bleaching procedures. J of Prosthet Dent. 2009;101(2):40-45.

24. Paul SJ, Peter A, Rodoni L, Pietrobon N. Conventional visual vs spectrophotometric shade taking for porcelain-fused-to-metal crowns: a clinical comparison. Internat J of Perio and Rest Dent. 2004;24(3):222-231.

25. Wee AG, Lindsey DT, Kuo S, Johnston. Color Accuracy of commercial digital cameras for use in dentistry. Dent Mater. 2006;22(6)553-559.

26. Carney MN, Johnston WM. A novel regression model from RGB image to spectroradiometric correlates optimized for tooth colored shades. J of Dent. 2016

27. Lagouvardos PE, Fougia AG, Diamantopoulou SA, PolyzoisGI. Repeatibility and interdevice reliability of two portable color selection devices in matching and measuring tooth color. J of Prosthet Dent. 2009;101(1):40-45.

28. Kim-Pusateri S, Brewer JD, Davis EL, Wee AG. Reliability and accuracy of four dental shade-matching devices. J Prosthet Dent. 2009;101(3):193-199. 